Voix et Images

voixetimages

\title{
Poélitique de Madeleine Gagnon
}

\section{Jean Fisette}

Volume 1, numéro 3, avril 1976

\section{Gérard Bessette}

URI : https://id.erudit.org/iderudit/200047ar

DOI : https://doi.org/10.7202/200047ar

Aller au sommaire du numéro

Éditeur(s)

Les Presses de l'Université du Québec

ISSN

0318-9201 (imprimé)

1705-933X (numérique)

Découvrir la revue

Citer cet article

Fisette, J. (1976). Poélitique de Madeleine Gagnon. Voix et Images, 1(3), 454-455. https://doi.org/10.7202/200047ar d'utilisation que vous pouvez consulter en ligne.

https://apropos.erudit.org/fr/usagers/politique-dutilisation/ 


\section{Poélitique de Madeleine Gagnon}

En lisant Poélitique ', on a l'impression d'un texte déconstruit, d'un discours qui se refuse à l'homogénéité, à l'univocité, et ceci pour atteindre une plus grande efficacité.

Il s'agit de fait, de la mise en parallèle de différents niveaux de discours-langages qui s'épaulent, s'inter-pénètrent, s'interprètent. D'abord une série d'événements d'ordre politique et syndical rythment le récit, le faisant avancer au fil d'une histoire du Québec des quinze dernières années: conflits de travail ou plutôt GRẺVES (puisqu'ici, aucune concession n'est faite aux euphémismes caractéristiques des média), BOMBES des premiers mouvements felquistes, Expo-, Élections, LOCK-OUT, Fondation de partis politiques, OCTOBRE, Alliances inter-syndicales (CLASSE DES TRAVAILLEURS), bref un condensé de titres sensationnels de journaux; en surimpression, la banale histoire, ou plus simplement, la timide présence de "Ti-Toine, fils de laitier, asteure chômeur", le prototype même du sujet même pas un individu - constamment dépassé par les événements, la victime idéale, quoi!

Un peu à l'image des graffes que le compilator médiéval inscrivait en marge des textes à commenter, on trouve des questions-interrogations sur le sens des événements rapportés, sur l'incapacité tragique à les interpréter, des contre-questions, ici affirmations sur le sens à leur donner, les autorités étant Brecht, Maïakovsky, Mao, Pleynet, Sollers; Mao-Zeudung...

Les commentaires viennent compenser l'absence d'organisation grammaticale - et idéologique? - des événements présentés comme sur une bande télégraphique sans fin, du “fait socio-politique à la verge". Si bien que le déroulement des actions (centré graphiquement) prend une valeur de marginalité, fonctionnant comme un indice de vraisemblance. Car le véritable débat qui est ici pro-posé (au sens d' "anté-posé ") se manifeste dans les commentaires: vanité, vacuité des intérêts supposément intellectuels (on lit ou bien /e Devoir, ou bien Guy des Cars); plus justement incapacité des «penseurs" à comprendre les faits. La contradiction se manifeste par exemple, entre le dogme marxiste et le projet de création d'une revue littéraire (Q.L.) vouée au "nombrilisme".

Une des significations qui se dégagent de Poélitique me semble-t-il, c'est la distance séparant ces trois plages graphiques: les événements, la poésie, les théories sociales. Blocs d'imprimés, mais aussi les pratiques sociales qu'ils figurent, qu'ils réalisent. C'est une constatation, à peu près partout admise aujourd'hui, que la désertion des intellectuels québécois de la scène politique depuis une huitaine d'années, constatation non proclamée comme une revendication, mais acceptée comme un destin. André 
Brochu ("Autour d'Octobre", dans Intervention $n^{\circ}$ 1) parle de «mystique formaliste". Je crois plutôt qu'on a compris que tout discours, tout langage est chargé ("aucune parole n'est innocente"), ce qui signifie la fin de la croyance à l'idéale objectivité de l'analyse. Les penseurs-écrivains se sont brusquement vus frappés d'interdit ou bien se sont lancés dans le langage d'action (Stratégie et, dans une moindre mesure, Chroniques). Mais le discours d'action (un langage chargé) est coercitif: on s'y engage comme "en religion" (prix au sens étymologique de "doublement lié ": une attache à deux sens).

Le recours moderne à la fonction médiévale du compilator réalise bien la disparition de l'auteur modelé sur l'image fascinante qu'en avait formée le xıxe siècle et révèle en plein jour les mécanismes de production du discours. Le a je "énonciateur, sujet à la fois grammatical et idéologique, ne se cache plus sous la surface lisse du texte; il s'inscrit, humblement, tout simplement, comme organisateur, afficheur. (La relation à L'Afficheur hurle de Chamberland est très visible.) Ce qu'on peut retenir de cette transformation du "rôle" assumé d'auteur, c'est l'effet de destruction du texte: le discours classique apparait comme un tableau, lieu de projection, de désir d'un auteur qui s'y exhibe et s'y refoule à la fois.

'J'ai parlé, en commençant, de Poélitique comme d'un texte éminemment parcellaire; de fait, la seule liaison qui existe est proposée dans l'effet (artificiel) de condensation dans le titre: POÉSIE LITIQUE. C'est là l'affiche d'une recherche, sans plus.

Poélitique fait le procès d'une auto-analyse du discours politique, aboutissant à son auto-destruction:

L'Ordre du discours s'instaure

dès même le graphe s'inscrit de l'interdit

qui est en cause.

Le discours traditionnel, très raisonnable, repose sur des interdits qu'il faudra transgresser: Le nouveau discours, s'il est possible, n'est pas près de naître (il lui faudra afficher ses interdits spécifiques) ou bien il ne pourra être que collage, collection, collation...

Jean Fisette

1. Les Herbes rouges, $\mathrm{n}^{\circ} \mathbf{2 6}$, février 1975. 